\title{
Partial Exclusion of Bacteriophage T2 by Bacteriophage T4: an Exclusion-resistant Mutation in Gene 56 of T2
}

\author{
By ROBERT J. H. OKKER,* ELISABETH PEES AND VICTOR BOM \\ Laboratory of Genetics, University of Leiden, Kaiserstraat 63, 2311 GP Leiden, The \\ Netherlands
}

(Accepted 23 September 1980)

SUMMARY

The early genes of bacteriophage $\mathrm{T} 2$ are partially excluded from the progeny of crosses between the related bacteriophages T2 and T4. This is due to complete exclusion from the progeny of six exclusion-sensitive sites in T2. A mutation [exr(56)1] in the sensitive site near $\mathrm{T} 2$ gene 56 renders the site partially resistant against exclusion.

This paper describes the mapping of the $\operatorname{exr}(56) 1$ mutation. The mutation was mapped between two clusters of amber 56 mutations in $\mathrm{T} 2$, but mapping was not completely unequivocal. Additional evidence for location of $\operatorname{exr}(56) 1$ within gene 56 was provided by the decrease in the activity of the gene 56 product (dCTPase: EC 3.6.1.12) induced by $\mathrm{T} 2 \operatorname{exr}(56) 1$ strains. The location of $\operatorname{exr}(56) 1$ within an essential gene contradicts the exclusion model proposed by Russell \& Huskey (1974).

\section{INTRODUCTION}

Bacteriophages T2 and T4 are closely related. Their genetic maps are nearly identical (Wood \& Revel, 1976; Russell, 1974) and their DNAs hybridize with each other (Kim \& Davidson, 1974). Most genes of both parents are present with approximately equal frequency in the recombinant progeny of crosses between $\mathrm{T} 2$ and $\mathrm{T} 4$, but the early genes of $\mathrm{T} 2$ are partially excluded. Six exclusion-sensitive sites have been identified in T2 and have been localized near the genes 32, 39, 56, 42, agt (Pees, 1970; Pees \& De Groot, 1970, 1975; Russell \& Huskey, 1974) and dam (E. Pees, unpublished data). The exclusion-sensitive sites are completely absent from the progeny and are characterized by loss of linkage of T2 markers on either side of them (Russell \& Huskey, 1974). The degree of exclusion of the early genes of $\mathrm{T} 2$ corresponds roughly with the distance to exclusion-sensitive sites.

One mutant of T2 [exr(56)1] has been isolated (Pees, 1970) that is partially resistant against exclusion of the exclusion-sensitive site near gene 56. The mutation is cis-dominant in crosses with wild-type $\mathrm{T} 2$ and therefore is probably a mutation in the exclusion-sensitive site. Mutants of T2 partially resistant against exclusion of other exclusion-sensitive sites have not been isolated despite extensive efforts. We report here more detailed analysis of the localization of the $\operatorname{exr}(56) 1$ mutation and show that it is located within gene 56 of $\mathrm{T} 2$.

\section{METHODS}

Phage and bacterial strains are described in Table 1. The presence of the exr mutation was established using a modification of the spot-tests described previously (Pees, 1970; Pees \& De Groot, 1975; Okker \& De Groot, 1978): lawns were prepared of a sup ${ }^{+} \mathrm{rgl}^{+}$host (non-suppressing for amber mutations, restrictive for glucoseless $\mathrm{T}$-even phage) mixed with $5 \times 10^{7} \mathrm{~T} 4 \mathrm{~B} 85$ particles. Drops of T2 $\alpha \mathrm{gt}$ on such a lawn do not show lytic development due 
Table 1. Bacteriophage and bacterial strains

Bacteriophage strain

T2 am 13, am61, am64

am 102, am 133, am 154b

am $165, a m \mathrm{FS} 2, a m \mathrm{FS} 18$

T2 $\operatorname{am} 86$

$\mathrm{T} 2 \mathrm{am} 3$

$\mathrm{T} 2 \alpha g t \mathrm{R}$

$\mathrm{T} 2 \operatorname{exr}(56) 1$

T2-4

T4 B 85

Escherichia coli strain $\mathbf{B} \boldsymbol{s}^{\mathrm{T}}$

K 704

$\mathrm{K} 12(\lambda) r 6 r 2.4$ sup $^{+}$ $\mathrm{K} 12(\lambda) r 6 r 2,4 s u p^{-}$ CR63

XA101

XA 102

XA103

XA 105

XA106

$\mathrm{XA10B}$

$\mathrm{XA} 10 \mathrm{C}$
Relevant properties

Amber in gene 56

Amber in gene 41

Amber in gene 42

Point mutation in gene $\alpha g t$

Partial exclusion resistance of T2 gene 56

A T2 $\times$ T4 hybrid with the early regions of T4 except $\mathrm{T} 2$-derived region of gene 56 ; late regions not defined

Amber in gene 56

Streptomycin resistant; sup $r g l^{+}$(restrictive
for glucoseless T-even phage)
sup $-2=$ supE; permissive for glucoseless
$\mathrm{T}$-even phage
rgl6rgl2,4sup ${ }^{+}$
rgl6rgl2,4supF
$r g l^{+}$sup $-1=$ supD
supD
supE
sup $\mathrm{F}$
supG
sup 6
sup $\mathrm{B}$
supC

Source or reference

Russell (1974) (obtained from Dr W. B. Wood)

Russell (1974)

Russell (1974)

Revel et al. (1965)

Pees (1970)

This laboratory (E. Pees, unpublished data)

This laboratory

Dr W. Harm

Dr R. L. Russell

Revel \& Georgopoulos (1969)

Revel \& Georgopoulos (1969)

Dr Ch. M. Steinberg

Miller et al. (1977)

Miller et al. (1977)

Miller et al. (1977)

Miller et al. (1977)

Miller et al. (1977)

Miller et al. (1977)

Miller et al. (1977)

to the exclusion of wild-type T2 gene 56. On the contrary, drops of T2 agt exr(56)1 show almost complete lysis due to the appearance of wild-type recombinants between T4 B85 and T2 agt exr(56)1. Exclusion was measured quantitatively with crosses of the type T4 $\mathrm{B} 85 \times \mathrm{T} 256^{+}$, with equal input of the parental phages. Crosses with the $\mathrm{T} 2^{+}$parent yielded less than $0.1 \%$ wild-type progeny, and crosses with the T2 $\operatorname{exr}(56) 1$ parent yielded $2 \%$ wild-type progeny. Unequal input crosses of the type $\mathrm{T} 456^{+} \times \mathrm{T} 2$ amber 56 were used to test for the presence of the $\operatorname{exr}(56) 1$ mutation in the T2 amber 56 strains. The input ratio of parental $\mathrm{T} 4: \mathrm{T} 2$ phages was $1: 20$. Out of the total progeny on a $\mathrm{Su}^{+}$indicator lawn, 100 progeny plaques were tested for the am marker. Crosses with T2 amber $56 \mathrm{exr}^{+}$yielded less than $1 \%$ am progeny, and crosses with a T2 amber $56 \operatorname{exr}(56) 1$ parent yielded 50 to $60 \%$ am progeny.

Triple T2 mutant strains with the exr(56)1 mutation, an amber 56 mutation and an $\alpha g t$ mutation were constructed as follows. Phage T2 agt exr(56)1 was crossed with the desired T2 amber 56 mutant with an input ratio of 20:1 respectively. The host was Escherichia coli K 704. The progeny of the cross was seeded on E. coli K 704 indicator lawns. Single progeny plaques were isolated and spot-tested for growth on $E$. coli $\mathrm{K} 12(\lambda) r 6 r 2,4$ sup $^{+}$and $E$. coli CR63. From the isolates showing no lytic response in both spots, $a m^{+}$revertants were isolated on $E$. coli $\mathrm{K} 12(\lambda) r 6 r 2,4 s u p^{+}$and the revertants were tested for the presence of the $\operatorname{exr}(56) 1$ mutation.

Three-point crosses for the localization of $\operatorname{exr}(56) 1$ (Table 3) were on E. coli K 704 host with equal input of the parents. The progeny of the crosses was seeded on $E$. coli $\mathrm{K} 12(\lambda) r 6 r 2,4 \mathrm{sup}^{+}$indicator lawns and isolated progeny $\mathrm{am}^{+}$were spot-tested for the presence of the $\operatorname{exr}(56) 1$ mutation. In crosses where one of the parents missed the agt mutation, a control spot-test on $\mathrm{B} s^{\mathrm{r}}$ without added T4 B85 indicated the presence of the $\alpha g t$ mutation. Only progeny isolates with $\alpha g t$ were considered. 


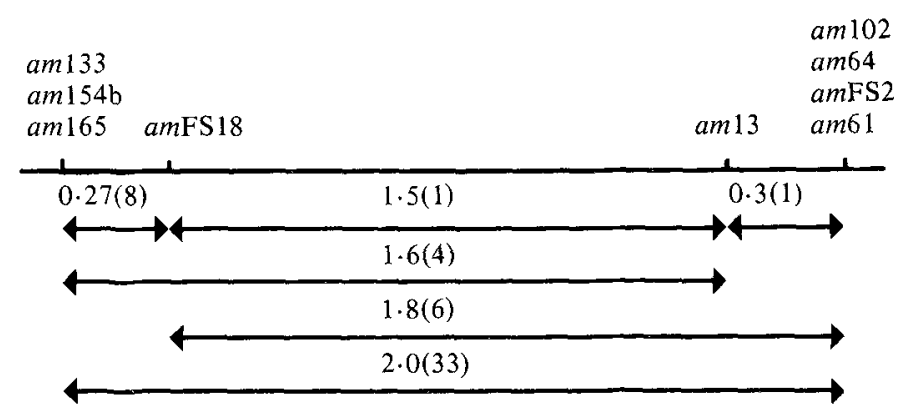

Fig. 1. Localization of T2 amber 56 mutations. Single T2 amber 56 mutants were crossed in $E$. coli K 704 host bacteria. The progeny was seeded on $E$. coli K 704 and Bs $s^{r}$ indicator lawns. Distances are percentage wild-type recombinants only (see text). The number of times each cross was done is given in brackets. Mutations depicted at the same position showed less than $7 \times 10^{-5}$ wild-type recombinants in mutual crosses.

Table 2. Efficiency of plating (e.o.p.) of T2 amber 56 strains

\begin{tabular}{|c|c|c|c|c|c|}
\hline \multirow[b]{2}{*}{$\begin{array}{c}\text { E. coli } \\
\text { indicator lawn }\end{array}$} & \multicolumn{5}{|c|}{ Bacteriophage strain* } \\
\hline & $\begin{array}{l}\operatorname{amFS2} ; \operatorname{am} 61 ; \\
\operatorname{am} 64 ; \operatorname{am} 102\end{array}$ & $\operatorname{am} 133 ; \operatorname{am} 154 \mathrm{~b} ; \operatorname{am} 165$ & amFS 18 & $\operatorname{am} 13$ & $\operatorname{am} 61 \operatorname{exr}(56) 1$ \\
\hline $\mathrm{XA101;supD}$ & + & + & + & + & + \\
\hline 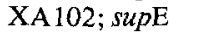 & + & + & + & + & + \\
\hline 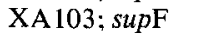 & + & - & + & - & - \\
\hline XA105; supG & - & - & + & - & - \\
\hline XA 106; sup6 & + & + & + & - & - \\
\hline $\mathrm{XA10B} ;$ supB & - & \pm & + & \pm & - \\
\hline $\mathrm{XA} 10 \mathrm{C} ;$ supC & - & - & - & - & - \\
\hline $\mathrm{B}_{s^{\mathrm{r}}} ; \mathrm{Su}^{-}$ & - & - & - & - & - \\
\hline
\end{tabular}

* Bacteriophage strains were seeded in appropriate dilution on indicator lawns and the e.o.p. was compared to the plaque count on the $\sup \mathrm{E}$ indicator. + , The same e.o.p. as on supE; \pm , reduced e.o.p. (80 to $1 \%)$, pin-point plaques; -, less than $1 \%$ e.o.p.

The assay of the gene product of gene 56, deoxycytidine triphosphate nucleotidohydrolase (dCTPase; EC 3.6.1.12), was essentially according to Wiberg et al. (1973). General phage techniques used have been described previously (Adams, 1959; Pees \& De Groot, 1975).

\section{RESULTS}

The T2 amber mutants in gene 56 (Table 1) were crossed with each other. The resulting genetic map is given in Fig. 1. Attempts to isolate T2 strains with two amber 56 mutations were unsuccessful. Therefore, the distances in the genetic map of Fig. 1 are given as percentage wild-type recombinants only. The amber mutations were found at four different positions on the genetic map. Each mutation at the same position was suppressed in the same nonsense-suppressor host and the mutations at each position showed a different pattern of suppression (Table 2). Therefore, amber mutations at the same position are probably identical.

The results of three-point crosses to localize the $\operatorname{exr}(56) 1$ mutation with respect to the gene 56 amber mutations are given in Table 3. The crosses T2 am61exr(56) $1 \times \mathrm{T} 2 \operatorname{am} 133$ (or T2 am $154 \mathrm{~b}$ ) showed $18.8 \%$ uncoupling between the $a m^{+}$allele of T2 am133 in T2 am61 and the $\operatorname{exr}(56) 1$ mutation. The cross T2 $\operatorname{am} 61 \operatorname{exr}(56) 1 \times \mathrm{T} 2$ amFS18 showed $16.4 \%$ uncoupling between the $\mathrm{am}^{+}$allele and $\operatorname{exr}(56) 1$. These results place the $\operatorname{exr}(56) 1$ mutation at 1.5 to $1.68 \%$ (single recombination) left from $a m 61$ in Fig. 1. Crosses designed to localize $\operatorname{exr}(56) 1$ with respect to the outside markers T2 am86 (gene 41) and T2 am3 (gene 42) placed $\operatorname{exr}(56) 1$ 
Table 3. Localization of the $\operatorname{exr}(56) 1$ mutation with respect to $T 2$ amber 56 mutations

Expt. no.
1
2
3
4
5
6

\begin{tabular}{|c|}
\hline Cross* \\
\hline $\begin{array}{l}\mathrm{T} 2 \text { am6 } \operatorname{exr}(56) 1 \alpha g t \times \mathrm{T} 2 \text { am } 133 \\
\mathrm{~T} 2 a m 61 \operatorname{exr}(56) 1 \alpha g t \times \mathrm{T} 2 \text { am } 133 \alpha g t \\
\mathrm{~T} 2 \text { am6 } 1 \operatorname{exr}(56) 1 \alpha g t \times \mathrm{T} 2 \text { am } 154 \mathrm{~b} \\
\mathrm{~T} 2 \text { am } 61 \operatorname{exr}(56) 1 \alpha g t \times \mathrm{T} 2 \text { amFS } 18 \\
\mathrm{~T} 2 \text { am } 133 \operatorname{exr}(56) 1 \alpha g t \times \mathrm{T} 2 \text { am6 lagt } \\
\mathrm{T} 2 \text { am } 133 \operatorname{exr}(56) 1 \alpha g t \times \mathrm{T} 2 \text { am6 } 1 \alpha g t\end{array}$ \\
\hline
\end{tabular}

exr among am ${ }^{+} \alpha g t$
recombinants
$6 / 47$
$45 / 235$
$8 / 32$
$32 / 195$
$195 / 196$
$113 / 114$

$\begin{gathered}\text { Mean } \\ \text { value }(\%)\end{gathered}$
$\left.\begin{array}{l}12 \cdot 8 \\ 19 \cdot 1 \\ 25 \cdot 0\end{array}\right\} 18 \cdot 8 \%$
$16 \cdot 4 \quad 16.4 \%$
$\left.\begin{array}{l}99 \cdot 5 \\ 99 \cdot 1\end{array}\right\} 99.4 \%$

* See Methods for details of selection. Crosses 1 to 3 were in the configuration:

$$
\frac{a m^{+} \operatorname{exr}(56) 1 a m 61}{a m 133+a m^{+}}
$$

crosses 5 and 6 were in the configuration:

$$
\frac{a m^{+}+a m 61}{a m 133 \operatorname{exr}(56) 1 \mathrm{am}^{+}}
$$

\section{Table 4. Isolation of $\mathrm{exr}^{+}$revertants from $T 2-4 \operatorname{am} 61 \operatorname{exr}(56) 1$}

$\begin{array}{ccccc}\text { Phage batch } & \text { Titre on K704 } & \begin{array}{c}\text { Frequency on* } \\ \mathrm{K} 12(\lambda) r 6 \mathrm{r} 2,4 \text { supF }\end{array} & \begin{array}{c}\text { Number of } \text { am }^{+} \\ \text {revertants isolated }\end{array} & \begin{array}{c}\text { Number of exr } \\ \text { revertants isolated }\end{array} \\ 1 & 2.4 \times 10^{10} & 2.5 \times 10^{-7} & 4 & 2 \\ 2 & 1.7 \times 10^{10} & 8.4 \times 10^{-7} & 12 & 2 \\ 3 & 2.8 \times 10^{10} & 9.6 \times 10^{-7} & 13 & 12\end{array}$

* A $0.1 \mathrm{ml}$ amount of $10^{-2}$ phage dilution was seeded on $E$. coli $\mathrm{K} 12(\lambda) r 6 r 2,4 s u p F$ indicator lawns. Revertants were isolated and spot-tested on $\mathrm{Bs}^{\mathrm{r}}==$ sup $\mathrm{p}^{+}$. Revertants not showing $a m^{+}$phenotype were assayed with the 'unequal-input' assay (see Methods).

at 1.5 to $1.6 \%$ (single recombination) left from am61 in the sequence am3, $\operatorname{am} 86$, $\operatorname{am} 61$, $\operatorname{exr}(56) 1$ (E. Pees, unpublished results).

The reciprocal cross $\mathrm{T} 2$ am $133 \operatorname{exr}(56) 1 \times \mathrm{T} 2$ am61 showed only $0.6 \%$ uncoupling between $\operatorname{am} 133$ and $\operatorname{exr}(56) 1$. Therefore, the localization of $\operatorname{exr}(56) 1$ is not unequivocally between the markers am 61 and am 133 (see Discussion). However, the following additional evidence supports the location of $\operatorname{exr}(56) 1$ in T2 gene 56.

Introduction of the $\operatorname{exr}(56) 1$ mutation into T2-4 am61 altered the suppression of the am61 mutation (Table 2). The double-mutant strain T2-4 am6 $\operatorname{exr}(56) 1$ did not grow on a supF or sup6 indicator strain in contrast to the single mutant strain T2-4 am61. The use of the hybrid strain T2-4 instead of T2 facilitated the tests for the presence of the $\operatorname{exr}(56) 1$ mutation. The T2-4 hybrid strain used contains the region around gene 56 of T2, and other early regions from T4. For the present investigation, only the facilitation of the spot-tests for exr(56)1 is relevant. Three separate cultures of $\mathrm{T} 2-4 \operatorname{am} 61 \operatorname{exr}(56) 1$ were seeded on a supF indicator lawn and revertants were isolated and tested for growth on a sup ${ }^{+}$host (Table 4). Two classes of revertants were isolated, one class with $\mathrm{am}^{+}$reversion (growth on $\mathrm{sup}^{+}$host) and one class with $\operatorname{exr}^{+}$reversion. The presence of the $\operatorname{exr}^{+}$reversion was verified with the 'unequal-input' assay.

Genetic analysis was complemented by measurement of enzyme activities of the gene 56 gene products (Table 5). The double-mutant strain T2-4 am6lexr(56)1 did grow on a supE host (Table 2) but the activity of gene 56 product, dCTPase, was 3.9 times lower in extracts from the T2-4 am6lexr(56)1-infected supE host than in extracts from T2-4 am61-infected cells (Table 5). Extracts from T2-4 exr(56)1-infected cells showed a twofold lower enzyme activity than extracts from T2-4 exr ${ }^{+}$-infected cells. Extracts from cells infected with the 
Table 5. Activity of dCTPase (gene 56 product) in extracts from phage-infected $\mathrm{E}$. coli K704 cells*

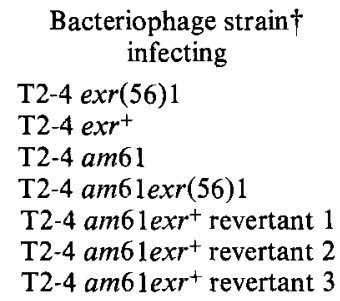

Activity of dCTPase
(nmol dCMP/min $/ 10^{9}$ cells)

$7 \cdot 7$

$15 \cdot 2$

$6 \cdot 7$

$1 \cdot 7$

$7 \cdot 8$

$12 \cdot 9$

$9 \cdot 1$

* Cells of $E$. coli $\mathrm{K} 704$ were infected with a multiplicity of infection of 6 . Extracts were made after $14 \mathrm{~min}$ incubation at $37^{\circ} \mathrm{C}$.

+ See Table 4 for construction of exr r revertants of T2-4 am61exr(56)1.

$\ddagger d C T P$ ase catalyses dephosphorylation of dCTP to dCMP. The figures given are mean values of duplicate determinations.

single-step $\mathrm{exr}^{+}$reversion (T2-4 am61exr ${ }^{+}$) showed a 1.2 to 1.9 times higher dCTPase activity than the control extract from T2-4 am61.

An identical analysis for T2 $\operatorname{am} 133 \operatorname{exr}(56) 1 \alpha g t$ was not successful because the recombinant strain appeared unstable. After overnight growth of the phage in a liquid bacterial culture, there was a nearly complete loss of the $\operatorname{exr}(56) 1$ mutation and a 100 -fold increase in $\mathrm{am}^{+}$revertants. After single-step multiplication in liquid culture in $\mathrm{K} 704$ the $\mathrm{am}^{+}$ reversion frequency as measured on $\mathrm{K} 12(\lambda) r 6 r 2,4 s u p^{+}$indicator lawns was $2 \times 10^{-5}$. Single plaques from these $\mathrm{am}^{+}$revertants were isolated and as many as $8 \%$ were found to have lost the $\operatorname{exr}(56) 1$ mutation also.

\section{DISCUSSION}

The mutant $\operatorname{exr}(56) 1$ of bacteriophage $\mathrm{T} 2$ is partially resistant against exclusion of the exclusion-sensitive site near gene 56. The mutation is probably in the exclusion-sensitive site. To map the exr(56)1 mutation more exactly, a genetic map of the T2 gene 56 was constructed with the use of amber mutations in gene 56 . The amber mutations available were found at four different positions. For the localization of $\operatorname{exr}(56) 1$ it is useful to know which segment of gene 56 is covered by the amber mutations. This can be estimated with some assumptions being made: the $\mathrm{am}^{+}$recombinants had no selective advantage over single $\mathrm{am}$ parents in the crosses; recombination in gene 56 of $\mathrm{T} 2$ is representative for $\mathrm{T}$-even recombination in general; and the amino acid composition of the gene product is about normal (39.8 mol. wt./base pair). Native T4 dCTPase has a mol. wt. of 60000 , and native T2 dCTPase has a mol. wt. of 51000 (Price \& Warner, 1969). The T4 enzyme consists of four identical subunits each with a mol. wt. of 15000 (O'Farrell et al., 1973). Assuming that this is true for T2 dCTPase also, the subunit of T2 dCTPase has a mol. wt. of 12750. A map unit corresponds to 70 base pairs (Stahl et al., 1964). The genetic distance between the ends of T2 gene 56 can thus be estimated to be $12750 / 39.8 \times 70=4.6$ map units. The distance between the most extreme am positions was 4.2 map units. The amber mutations thus cover about $91 \%$ of the T2 gene 56 .

In the crosses between amber mutants, the class of double amber mutants was not recovered. Loss of this class, due to very low activity of the induced dCTPase (see below), in the $s u p^{-}$indicator strains used seems the most probable assumption for this deficiency. The lack of the double amber class restricted three-point localization of $\operatorname{exr}(56) 1$ to crosses of the type $a m \operatorname{exr}(56) 1 \times a m$. 
The first series of crosses localized $\operatorname{exr}(56) 1$ between the am 61 and am 133 mutations, in accordance with crosses that established the sequence gene 41, am61, exr(56)1. However, the reciprocal crosses showed close coupling of $\operatorname{exr}(56) 1$ with the am 133 marker as a result of the low proportion of $a m^{+}$recombinants that possess the $\operatorname{exr}(56) 1$ mutation. A low frequency of progeny with $\operatorname{exr}(56) 1$ would also be found if the mutation is lost during multiplication during the cross. The strain $\operatorname{am} 133 \operatorname{exr}(56) 1$ is evidently unstable as inferred from the high proportion of revertants. This instability seems an extreme example of the influence of $\operatorname{exr}(56) 1$ on the activity of the gene product. The reciprocal crosses are not conclusive for the intragenic location of $\operatorname{exr}(56) 1$.

The enzyme activity of the gene 56 product, dCTPase, was 15.2 units in extracts of wild-type T2-4-infected $E$. coli K 704 cells (Table 5). The am61 mutation was suppressed in the host $E$. coli $\mathrm{K} 704$ sup $\mathrm{E}$ but the enzyme activity in extracts from am61-infected cells was $2 \cdot 3$ times lower than in the control. The supE host evidently inserts an amino acid that restores the enzyme activity to a great extent but not completely. Not all amino acid insertions are useful at the $a m 61$ position because $\sup \mathrm{G}, \sup \mathrm{B}$ and $\sup \mathrm{C}$ did not suppress the am61 mutation. Extracts of T2-4 exr(56)1-infected cells showed a twofold lower activity than the control. This observation suggests that $\operatorname{exr}(56) 1$ is a non-lethal missense mutation in gene 56. The strain T2-4 $\operatorname{am} 61 \operatorname{exr}(56) 1$ only grew on a supD and a sup $\mathrm{E}$ host and extracts from T2-4 am61exr(56)1-infected K704 cells were 8.9 times lower in enzyme activity than the wild-type control. The enzyme activity was two times lower than could be expected from the combination of mutations. The two mutations show synergism in decreasing the enzyme activity and only some amino acids are acceptable for a functional enzyme at the am 61 position when $\operatorname{exr}(56) 1$ is present. Although the T2-4 am61exr(56)1-induced dCTPase is 8.9 times less functional in vitro than wild-type enzyme, T2 am61 exr(56)1 grows well on $E$. coli K704 indicator lawns. This indicates that dCTPase levels in wild-type infections are not critical. Possibly the combination am133exr(56)1 decreases the enzyme activity even more and this leads to a selective advantage for wild-type revertants during multiplication, causing the genetic instability of $\mathrm{T} 2 \operatorname{am} 133 \operatorname{exr}(56) 1$.

Revertants of $\operatorname{exr}(56) 1$ in T2-4 $\operatorname{amb} \operatorname{lexr}(56) 1$ could be isolated and the isolates were independent of each other (Table 4). Extracts from cells infected with the revertant strains showed recovery of enzyme activity, indicating that the decrease in enzyme activity was due to the $\operatorname{exr}(56) 1$ mutation and not to an uncontrolled mutation. The influence of the $\operatorname{exr}(56) 1$ mutation on dCTPase activity provides additional evidence for location of exr(56)1 in gene 56. The mutation is apparently in an exclusion-sensitive site and a non-lethal missense mutation in gene 56 .

Two models for partial exclusion have been proposed. A model comparable to restriction has been proposed (Hattman, 1964; Masamune, 1968; Mahmood \& Lunt, 1972) but the breakdown of parental T2 DNA, essential for the model, could not be confirmed by one of us (Okker, 1974). Russell \& Huskey (1974) made a proposal for the evolutionary origin of the exclusion properties of $\mathrm{T} 4$. The main point in the model was the assumption of an episome-like factor integrating in an exclusion-sensitive site of the T2-like T4 progeny. Our localization of an exclusion-sensitive site within an essential gene conflicts with this model. It seems improbable that an episome could integrate in an essential gene without destroying the proper gene functioning and consequently, the viability of the recombination product.

We thank Mrs K. P. Hasper-Voogt who did part of the experimental work.

\section{REFERENCES}

ADAMS, M. H. (1959). Bacteriophages. New York: Interscience.

HATTMAN, s. (1964). The functioning of T-even phages with unglucosylated DNA in restricting Escherichia coli host cells. Virology 24, 333-348. 
KIM, J-S. \& DAVIDsON, N. (1974). Electron microscope heteroduplex study of the sequence relation of T2, T4 and T6 bacteriophage DNAs. Virology 57, 93-111.

MAHMOOD, N. \& LUVT, M. R. (1972). Biochemical changes during mixed infections with bacteriophages T2 and T4. Journal of General Virology 16, 185-197.

MASAMUNE, Y. (1968). The effect of ultraviolet light on the intracellular stability of the DNA of bacteriophages T2 and T4. Molecular and General Genetics 101, 99-110.

MILleR, J. H., GANEM, D., LU, P. \& SCHMITZ, A. (1977). Genetic studies of the lac repressor. I. Correlation of mutational sites with specific amino acid residues: construction of a colinear gene-protein map. Journal of Molecular Biology 109, 275-301.

o'fARRELL, P. Z., GOLD, L. M. \& HUANG, W. M. (1973). The identification of prereplicative bacteriophage T4 proteins. Journal of Biological Chemistry 248, 5499-5501.

OKKER, R. J. H. (1974). The fate of parental DNA of bacteriophage T2 in crosses with bacteriophage T4. Biochimica et Biophysica Acta 353, 36-44.

OKKER, R. J. H. \& DE GROOT, B.-(1978). Specificity of partial exclusion of bacteriophage T2 in crosses with T4. Journal of General Virology 40, 705-709.

PEES, E. (1970). Bacteriophage T4 mutants unable to exclude gene 56 of T2 from the progeny of crosses. Mutation Research 9, 345-348.

PEES, E. \& DE GROOT, B. (1970). Partial exclusion of genes of bacteriophage T2 with T4-glucosylated DNA in crosses with bacteriophage T4. Genetica 41, 541--550.

PEES, E. \& DE GROOT, B. (1975). Mutants of bacteriophage T4 unable to exclude T2 from the progeny of crosses. Virology 67, 94-106.

PRICE, A. R. \& WARNER, H. R. (1969). Bacteriophage T4-induced deoxycytidine triphosphate-deoxyuridine triphosphate nucleotidohydrolase: its properties and its role during phage infection of Escherichia coli. Virology 37, 882-892.

REVEL, H. R. \& GEORGOPOULOS, C. P. (1969). Restriction of non-glucosylated T-even bacteriophages by prophage P1. Virology 39, 1-17.

REVEL, H. R., HATTMAN, S. \& LURIA, s. E. (1965). Mutants of bacteriophage T2 and T6 defective in $\alpha$-glucosyltransferase. Biochemical and Biophysical Research Communications 18, 545-550.

RUSSELL, R. L. (1974). Comparative genetics of the T-even bacteriophages. Genetics 78, 967-988.

RUSSELL, R. L. \& HUSKRY, R. J. (1974). Partial exclusion between T-even bacteriophages: an incipient genetic isolation mechanism. Genetics 78, 989-1014.

STAHL, F. W., EDGAR, R. S. \& STEINBERG, J. (1964). The linkage map of bacteriophage T4. Genetics 50, 539-552.

WIBERG, J. S., MENDELSOHN, S., WARNER, v., HERCULES, K., ALDRICH, C. \& MUNRO, J. L. (1973). SP62. a viable mutant of bacteriophage T4D defective in regulation of phage enzyme synthesis. Journal of Virology 12 , $775-792$

WOOD, W. B. \& REVEL, H. R. (1976). The genome of bacteriophage T4. Bacteriological Reviews 40, 847-868.

(Received 19 June 1980) 